3 Wallace, J., Milne, G. R., and Barr, A., British Medical fournal, 1972, $1,663$.

4 Schuurs, A. H. W. M., and Kacaki, J., Vox Sanguinis, 1974, 27, 97.

5 Jarboe, R. H., personal communication.

6 Cayzer, I., et al., Lancet, 1974, 1, 947.

7 Prince, A. M., et al., Lancet, 1973, 1, 1346

8 Prince, A. M., et al., Lancet, 1973, 1,

9 Prince, A. M., and Jass, D., Vox Sanuinis, 1974, 26, 209.

10 Arndt-Hanser, A., et al., Lancet, 1974, 2, 345.
11 Prince, A. M., et al., Lancet, 1974, 2, 241.

12 Public Health Laboratory Service, British Medical fournal, 1974, 4, 751.

13 Ling, C. M., and Overby, L. R., Fournal of Immunology, 1974, 109, 834

14 Reesink, H.' W., Duimel, W. J., and Brummelhuis, H. G. J., Lancet, 1973, 2, 1351.

15 Wallace, J., Lancet, 1973, 1, 1002.

16 Wallace, J., Proceedings of the Royal Society of Edinburgh, 1972, 71, s7.

17 Vandervelde, E. M., et al., Lancet, 1974, 2, 1006.

\title{
Plasma Nicotine Levels after Smoking Cigarettes with High, Medium, and Low Nicotine Yields
}

\author{
M. A. H. RUSSELL, \\ C. WILSON, \\ U. A. PATEL, \\ C. FEYERABEND, P.V. COLE
}

British Medical fournal, 1975, 2, 414-416

\begin{abstract}
Summary
Plasma nicotine three minutes after smoking a cigarette was measured in 10 sedentary workers in mid-morning and five hours later on four typical working days. The average mid-morning level after they had been smoking their usual cigarettes (mean nicotine yield $1.34 \mathrm{mg}$ ) was $150.4 \mathrm{nmol} / 1$ (24.4 $\mathrm{ng} / \mathrm{ml}$ ) (range 95.6-236.7 nmol/1 (15.5$38.4 \mathrm{ng} / \mathrm{ml}$ )). Despite great variation between smokers the mid-morning levels of each smoker were fairly consistent over the four mornings and correlated 0.82 with their carboxyhaemoglobin levels. After continuing to smoke their usual brand or switching to a high-nicotine brand (3.2 $\mathrm{mg}$ ) average afternoon levels of 185.6 and $180.0 \mathrm{nmol} / 1(30.1$ and $29.2 \mathrm{ng} / \mathrm{ml})$ respectively were not significantly higher than the morning levels, but after switching to low-nicotine cigarettes $(0 \cdot 14 \mathrm{mg})$ the plasma nicotine dropped to an average of $52.4 \mathrm{nmol} / 1(8.5 \mathrm{ng} / \mathrm{ml})$. The changes between morning and afternoon while smoking usual or high-nicotine cigarettes showed marked individual variation. The findings suggest that the plasma nicotine level just after a cigarette depends more on the way the cigarette is smoked than on its nicotine yield or the number which have been smoked over the preceding few hours.
\end{abstract}

\section{Introduction}

Official tables listing the tar and nicotine yields of cigarettes are based on the rigidly standardized and unvaried puffing of smoking machines. This is entirely appropriate for the comparison of cigarette brands but has trapped many into assuming too directly the implications for less hazardous smoking. Almost universally the public are recommended that, in the interest of their health, if they cannot stop smoking cigarettes they should try to switch to the low-tar, low-nicotine brands.

But people are not smoking machines. Even though some smokers may take a $35-\mathrm{ml}$, two-second puff once a minute to a butt length of $20 \mathrm{~mm}$ or the tip overwrap plus $3 \mathrm{~mm}$, which-

\footnotetext{
Addiction Research Unit, Institute of Psychiatry, Maudsley Hospital, London SE5 8AF

M. A. H. RUSSELL, M.R.C.P., M.R.C.PSYCH., Senior Lecturer and Honorary

Consultant
C. WILSON, B.SC., Research Worker

C. WILSON, B.SC., Research Wo
U. A. PATEL, M.SC., Statistician

Poisons Unit, New Cross Hospital, London S.E.14

Poisons Unit, New Cross Hospital, Lond

St. Bartholomew's Hospital, London, E.C.

P. V. COLE, M.B., F.F.A. R.C.S., Consultant Anaesthetist
}

ever is the greater, there is no guarantee that they will smoke a cigarette in the same way irrespective of its nicotine yield. Indeed, the evidence is to the contrary. Smokers terd to respond to changes in the tar and nicotine yields of cigarettes by altering their smoking pattern to regulate the nicotine intake. ${ }^{1-3}$ When the nicotine yield is high they tend to smoke less, and when it is low they compensate by smoking more. Since tar and nicotine yields of currently available cigarettes correlate so highly $(r=0.96)$ it has still to be proved that the adjustment relates to nicotine and not to tar or some other covarying component.

Apart from the number of cigarettes smoked there are more subtle ways in which a smoker may consciously or unconsciously alter his nicotine intake. Puff-size, puff-velocity, puff-rate, number of puffs per cigarette, proximity of puffs to tip, proportion of puff inhaled, and depth and duration of inhalation are some of the more obvious factors. Hitherto, the most sophisticated measure of nicotine intake has been by the analysis of nicotine in cigarette butts, ${ }^{34}$ which makes use of the close linear relation between the amount of nicotine deposited in the filter and the amount which passes through it. But even this tells us only how much the smoker has taken into his mouth.

For quantitative study the measurement of nicotine in urine is limited by the $\mathrm{pH}$ dependence of its excretion, and for various reasons it has been difficult to measure in blood. A reliable blood method has now been developed, ${ }^{5}$ and we have investigated the plasma nicotine levels in different smokers and the degree to which an individual smoker shows a consistent level on different days, at different times of the day, and when smoking cigarettes with different nicotine yields.

\section{Subjects and Methods}

Ten clerical and social workers volunteered to take part in the study. They were all regular cigarette smokers who said that they inhaled deeply. Venous blood samples were taken between 10 a.m. and $11.30 \mathrm{a} . \mathrm{m}$. and again about five hours later ( 3 p.m. to 4.30 p.m.) on four typical working days: two days of one week (days 1 and 2) and the same two days of the following week (days 3 and 4). For each subject the blood was taken at the same time on all four days. To avoid variations due to different time-spans between the last cigarette and collection of the samples the volunteers smoked a cigarette immediately before each sample, which was then taken three minutes after completion of the cigarette. On the morning of each day of study the subjects smoked their usual brand in the usual way. For the five hours between sampling they were given a liberal supply of cigarettes with instructions to smoke as much or as little as they wanted but not to offer or accept cigarettes from other people. On days 1 and 3 they were given their usual brand, but on days 2 and 4 they were given a high- or low-nicotine cigarette according to a balanced crossover design.

The high nicotine cigarette used was Capstan Full Strength (tar $38 \mathrm{mg}$, nicotine $3.2 \mathrm{mg}$ ) and the low nicotine cigarette Silk Cut 
Extra Mild (tar $4 \mathrm{mg}$, nicotine $0.14 \mathrm{mg}$ ). The brand identity was not concealed from the smokers. The number of cigarettes smoked during the five-hour period was estimated by subtracting those remaining from the number in the full packet. The cigarette ends were also stored in special containers, which provided a check on the number smoked.

The venous blood samples were collected into heparinized syringes. After an aliquot for nicotine estimation had been transferred to another container the syringes were capped and stored on ice until analysis for carboxyhaemoglobin ( $\mathrm{COHb}$ ), which was done on the same day. The specimens for nicotine estimation were separated within two hours and the plasma kept frozen until analysis. Blood $\mathrm{COHb}$ was measured with an I.L. $182 \mathrm{CO}$-Oximeter. ${ }^{6}$ Blood nicotine was estimated with a gas chromatograph. The method is accurate, reliable, and capable of measuring nicotine levels down to $0.62 \mathrm{nmol} / 1$ $(0.1 \mathrm{ng} / \mathrm{ml}){ }^{5}$ The laboratory analyses were carried out without knowledge of the design of the study or the cigarettes the subjects had been smoking. The subjects' urinary $\mathrm{pH}$ was not controlled.

Statistical analysis was by Student's $t$ test, analysis of variance, and Spearman's rank correlation statistic.

\section{Results}

Mid-morning Plasma Nicotine Levels.-The average mid-morning plasma nicotine on the four different days varied considerably between smokers $(F=18.1 ;$ D.F. $9 / 27 ; P<0.001)$ and ranged from 95.6 to $236.7 \mathrm{nmol} / 1(15 \cdot 5-38.4 \mathrm{ng} / \mathrm{ml}$ ) (see table). The small standard errors indicate that the mid-morning level of each individual smoker was fairly consistent over the four mornings. There was, however, some variation between days $(F=4.1 ;$ D.F. $3 / 27 ; P<0.05)$, which was due to a tendency for the morning levels to be slightly higher on day 3 (mean $172.6 \mathrm{nmol} / 1(28.0 \mathrm{ng} / \mathrm{ml})$ ) compared with the other three days (means $132 \cdot 6,140 \cdot 6$, and $154 \cdot 8 \mathrm{nmol} / 1(21 \cdot 5,22 \cdot 8$, and $25 \cdot 1 \mathrm{ng} /$ $\mathrm{ml})$ ). There was no relation between the mid-morning nicotine level and the subjects' usual cigarette consumption or the nicotine yield of their usual brand of cigarette $(r=-0.33$ and -0.04 respectively).

Changes in Number of Cigarettes Smoked.-When the smokers were smoking their usual brand of cigarette the number smoked over the five-hour experimental period was fairly consistent from one week to the next $(r=0.75 ; P<0.02)$, the means for the first and second week being 10.5 and 10.8 respectively. On changing to the low-nicotine cigarettes the numbers smoked increased to a mean of $12 \cdot 5$, but this increase was not statistically significant $(t=1.8$; D.F. 9). On changing to the high nicotine cigarettes, however, there was a $38 \%$ decrease in the numbers smoked to a mean of $6.7(t=3.8$; D.F. $9 ; \mathrm{P}<0.01)$ The difference was greater when the average number of low and high nicotine cigarettes smoked was compared $(12.5$ v. $6 \cdot 7 ; t=5 \cdot 3$; D.F. $9 ; \mathrm{P}<0.001$ )

Afternoon Plasma Nicotine Levels.-In the case of both usual and high-nicotine brands the afternoon levels were, on average, a little higher than in the morning but the differences were not statistically significant, neither was the difference between the afternoon levels after smoking the usual and high-nicotine brands. As might be expected the individual variation was greater after smoking the unfamiliar high-nicotine brand (S.D. $=90.0$ compared with 54.9 and 67.8 for the two afternoons on the usual brand). With both usual and highnicotine brands there were some smokers who showed an increase between morning and afternoon levels, but in others the afternoon levels were similar or slightly lower than in the morning (see table and fig. 1). There was no relation between the afternoon level and the number of cigarettes smoked in the preceding five-hour period $(r=$ -0.16 and 0.33 for usual and high-nicotine brands respectively). There was, however, a positive relation between the change in nicotine level between morning and afternoon and the number of cigarettes smoked over the five-hour period in the case of the high-nicotine

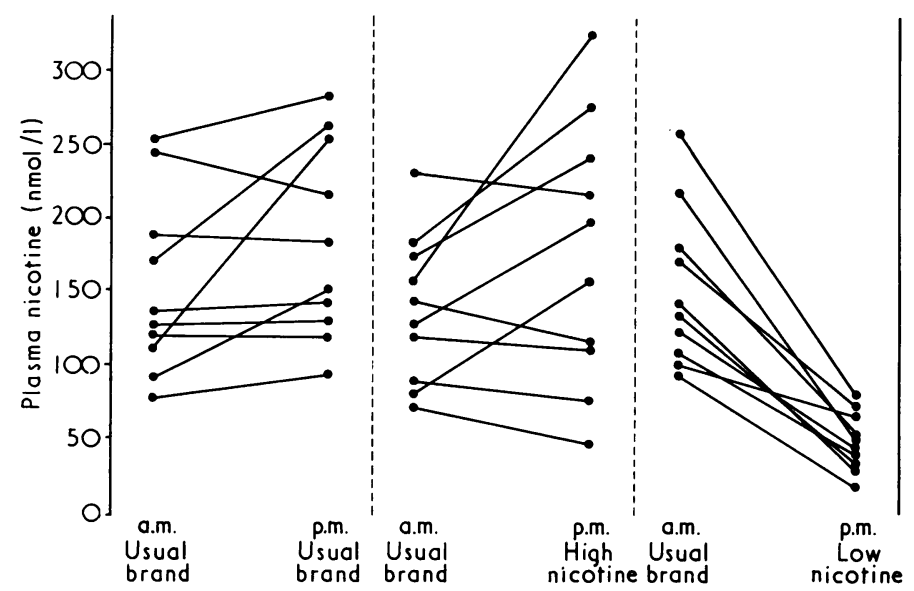

FIG. 1-Changes in plasma nicotine levels after five hours of smoking usual, high-nicotine, and low-nicotine cigarettes. Morning and afternoon levels on usual brand are means of two days' values.

Conversion: SI to Traditional Units-Nicotine: $10 \mathrm{nmol} / 1 \approx 1.62 \mathrm{ng} / \mathrm{ml}$.

Cigarette Consumption and Blood Nicotine Levels of Sedentary Workers Before and After Five Hours of Smoking High-nicotine, Low-nicotine, and Usual Cigarettes

\begin{tabular}{|c|c|c|c|c|c|c|c|c|c|c|c|}
\hline \multirow{3}{*}{$\begin{array}{l}\text { Case } \\
\text { No. }\end{array}$} & \multirow{3}{*}{$\begin{array}{l}\text { Age } \\
\text { and } \\
\text { Sex }\end{array}$} & \multicolumn{3}{|c|}{ Usual Cigarettes Smoked } & \multicolumn{3}{|c|}{$\begin{array}{l}\text { Number of Cigarettes Smoked } \\
\text { over Five Hours }\end{array}$} & \multicolumn{4}{|c|}{ Blood Nicotine (nmol/1) } \\
\hline & & \multirow{2}{*}{ Brand } & \multirow{2}{*}{$\begin{array}{l}\text { Nicotine } \\
\text { Yield } \\
\text { (mg) }\end{array}$} & \multirow{2}{*}{ No./Day } & \multirow{2}{*}{$\begin{array}{l}\text { Usual* } \\
\text { Brand }\end{array}$} & \multirow{2}{*}{$\begin{array}{l}\text { High } \\
\text { Nicotine }\end{array}$} & \multirow{2}{*}{$\begin{array}{l}\text { Low } \\
\text { Nicotine }\end{array}$} & \multirow{2}{*}{$\begin{array}{c}\text { Initial } \\
\text { Mid-morning } \\
\text { Level (Mean } \\
\pm \text { S.E. of } \\
\text { Mean) } \dagger\end{array}$} & \multicolumn{3}{|c|}{ Afternoon Levels Five Hours Later } \\
\hline & & & & & & & & & Usual Brand* & $\overline{\text { High Nicotine }}$ & Low Nicotine \\
\hline 1 & $25 \mathrm{M}$ & $\begin{array}{l}\text { Player's } \\
\text { No. } 6 \\
\text { Filter }\end{array}$ & $1 \cdot 2$ & 25 & $11 \cdot 0$ & 8 & 9 & $181 \cdot 9 \pm 17 \cdot 9$ & $180 \cdot 6$ & $326 \cdot 8$ & $55 \cdot 5$ \\
\hline 2 & $19 \mathrm{M}$ & $\begin{array}{c}\text { Embassy } \\
\text { Filter }\end{array}$ & $1 \cdot 3$ & 30 & $8 \cdot 5$ & 7 & 15 & $174.5 \pm 17 \cdot 9$ & $258 \cdot 9$ & 243.5 & $77 \cdot 1$ \\
\hline 3 & $20 \mathrm{~F}$ & $\begin{array}{c}\text { Embassy } \\
\text { Filter }\end{array}$ & $1 \cdot 3$ & 17 & $5 \cdot 0$ & 4 & 8 & $135 \cdot 6 \pm 3 \cdot 7$ & $146 \cdot 7$ & $117 \cdot 1$ & $52 \cdot 4$ \\
\hline 4 & $23 \mathrm{~F}$. & $\begin{array}{l}\text { Gitanes } \\
\text { Caporal } \\
\text { Filter }\end{array}$ & $1 \cdot 4$ & 35 & $14 \cdot 0$ & 9 & 13 & $129 \cdot 5 \pm 15 \cdot 4$ & $129 \cdot 5$ & $200 \cdot 4$ & $40 \cdot 1$ \\
\hline 5 & $22 \mathrm{~F}$ & $\begin{array}{c}\text { Embassy } \\
\text { Filter }\end{array}$ & $1 \cdot 3$ & 30 & $17 \cdot 5$ & 5 & 17 & $101 \cdot 7 \pm 19 \cdot 1$ & $157 \cdot 2$ & $52 \cdot 4$ & $39 \cdot 0$ \\
\hline 6 & $25 \mathrm{M}$ & $\begin{array}{c}\text { Rothman's } \\
\text { King Size }\end{array}$ & $1 \cdot 4$ & 35 & $12 \cdot 0$ & 6 & 15 & $106 \cdot 7 \pm 7 \cdot 4$ & $258 \cdot 9$ & $80 \cdot 1$ & $71 \cdot 0$ \\
\hline 7 & $63 \mathrm{M}$ & $\begin{array}{l}\text { Player's } \\
\text { Weights } \\
\text { Plain }\end{array}$ & $1 \cdot 6$ & 18 & $10 \cdot 5$ & 7 & 14 & $231 \cdot 2 \pm 23 \cdot 4$ & $286 \cdot 7$ & $280 \cdot 5$ & $74 \cdot 0$ \\
\hline 8 & $26 \mathrm{~F}$. & $\begin{array}{l}\text { Player's } \\
\text { Gold Leaf }\end{array}$ & 1.5 & 35 & $8 \cdot 5$ & 8 & 15 & $108 \cdot 5 \pm 9 \cdot 9$ & $123 \cdot 3$ & $160 \cdot 3$ & $43 \cdot 2$ \\
\hline 9 & $48 \mathrm{~F}$. & $\begin{array}{l}\text { Player's } \\
\text { No. } 6 \\
\text { Filter }\end{array}$ & $1 \cdot 2$ & 25 & $7 \cdot 5$ & 5 & 10 & $236 \cdot 7 \pm 21 \cdot 6$ & $215 \cdot 8$ & $221 \cdot 9$ & $49 \cdot 3$ \\
\hline 10 & $29 \mathrm{~F}$ & $\begin{array}{r}\text { Player's } \\
\text { No. } 6 \\
\text { Filter } \\
\end{array}$ & $1 \cdot 2$ & 22 & $12 \cdot 0$ & 8 & 9 & $95 \cdot 6 \pm 10 \cdot 5$ & $98 \cdot 6$ & $114 \cdot 1$ & $24 \cdot 7$ \\
\hline Mean & \pm S.D. & & $1 \cdot 34 \pm 0 \cdot 13$ & $27 \cdot 2 \pm 6 \cdot 86$ & $10 \cdot 7 \pm 3 \cdot 5$ & $6 \cdot 7 \pm 1 \cdot 6$ & $12 \cdot 5 \pm 3 \cdot 2$ & $150 \cdot 4 \pm 54 \cdot 3$ & $185 \cdot 6 \pm 66 \cdot 0$ & $180 \cdot 0 \pm 90 \cdot 0$ & $52 \cdot 4 \pm 17 \cdot 3$ \\
\hline
\end{tabular}

* Mean of values on two different days.

$\dagger$ Mean of levels on four different mornings after smokers smoked their usual brand in their usual way.

Conversion: SI to Traditional Units-Nicotine: $10 \mathrm{nmol} / 1 \approx 1 \cdot 62 \mathrm{ng} / \mathrm{ml}$. 
brand ( $r=0.78 ; P<0.01)$, but not for the usual brand $(r=0.16)$. After changing to the low-nicotine cigarettes the afternoon nicotine levels in all subjects decreased dramatically from the morning level obtained by smoking the usual brand $(t=8.4 ;$ D.F. $9 ; \mathrm{P}<0.001)$.

Correlation with $\mathrm{COHb}$ Levels. - An analysis of the $\mathrm{COHb}$ changes has been published." The relation of the nicotine levels to $\mathrm{COHb}$ levels for the mid-morning samples on the four days are plotted in fig. 2.

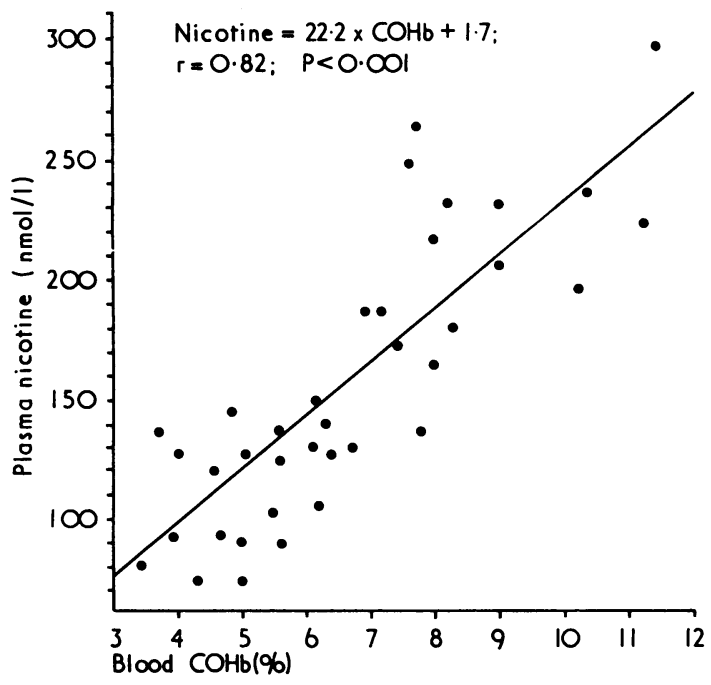

FIG. 2-Mid-morning plasma and $\mathrm{COHb}$ levels three minutes after a cigarette in 10 subjects who had smoked their usual cigarettes.

\section{Discussion}

Despite the great variation between smokers the mid-morning nicotine levels of each smoker were fairly consistent over the four mornings of the study. After continuing to smoke their usual brand or changing to the high-nicotine cigarettes the average afternoon levels were not significantly higher than the morning levels, but after changing to the low-nicotine cigarettes the plasma nicotine dropped significantly $(P<0.001)$.

While smoking the high-nicotine brand the average number of cigarettes smoked was reduced by $38 \%(P<0.01)$, which suggests that the subjects were, knowingly or unknowingly, adjusting their smoking to regulate their nicotine intake. This is supported by the fact that after five hours of smoking highnicotine cigarettes the plasma nicotine just after a cigarette was, on average, the same as after smoking the usual brand. Since the blood samples were taken only three minutes after a cigarette was smoked it seems that, as well as smoking fewer cigarettes, smokers adjust to a stronger cigarette by smoking differently. It should be emphasized, however, that individual variation was great and that some smokers did havehigher plasma nicotine levels after smoking the high-nicotine cigarettes, but owing to the small number of subjects, the limited number of blood samples taken, and the lack of $\mathrm{pH}$ control we could not identify different individual patterns.

The low-nicotine cigarettes used in this study were unfortunately too extreme. Their nicotine yield was barely onetenth that of the subjects' usual brand and to have obtained similar plasma nicotine levels with them would have been virtually impossible. The drop in plasma nicotine after smoking these cigarettes occurred despite the slight increase in the numbers smoked. It may have been their excessively high draw resistance or their inability to produce a pharmacological effect which prevented the subjects from significantly increasing consumption to compensate for the low nicotine yield. Inability to maintain an adequate blood nicotine level with these very low-nicotine cigarettes may account for their lack of acceptability to most smokers.

Apart from the wide individual variation the actual plasma nicotine level obtained by each subject bore no relation to his usual cigarette consumption, to the number of cigarettes smoked during the preceding five hours, or even to the nicotine yield of the cigarettes smoked (except for the low-nicotine cigarettes which were too low to permit self-regulation of nicotine dose). In other words the plasma nicotine level just after a cigarette seems to depend more on the way the cigarette is smoked than on its nicotine yield or the number smoked over the preceding few hours. The closer relation to the most recent cigarette is in keeping with a short half life, and the half life for nicotine has been shown to be under 30 minutes. ${ }^{8}$ But a cumulative effect was also shown in two smokers who smoked a cigarette every 30 minutes. In our study the overall tendency was for the afternoon nicotine levels to be similar to the morning levels despite the fact that the average rate of smoking was just over one cigarette every 30 minutes. This perhaps lends support to the view that smokers modify their smoking to regulate their nicotine intake in ways other than crude number of cigarettes smoked.

It is impossible to say how much (or which) subjects were smoking to obtain a certain nicotine level or whether the levels obtained were incidental to factors other than nicotine which determine the consistency or diurnal variation of an individual's smoking pattern. The true situation is likely to be much more complex in that even among those subjects who do smoke to obtain a certain nicotine level the actual level required may vary according to external circumstances and internal state. ${ }^{2}$,

The plasma nicotine levels were in line with those found in studies using gas chromatography ${ }^{8}$ and cigarettes impregnated with ${ }^{14} \mathrm{C}$-nicotine. ${ }^{10}$ The consistency and extent of the decrease in plasma nicotine on switching to the extremely low-nicotine brand provides some validation of our measurement of plasma nicotine. Further validation is provided by the positive correlation to COHb. This correlation would have been higher had the comparison been made with the increase in $\mathrm{COHb}$ after smoking one cigarette, for the nicotine level depends more on the smoking of the most recent cigarette, whereas the longer half life of $\mathrm{COHb}$ makes its level more dependent on the previous few hours of smoking.

In conclusion, assumptions as to the relative hazards of different brands of cigarettes which are based simply on the analysis of yields from a smoking machine are an important first step but likely to be seriously misleading if not backed up by study of the responses of smokers. Determination of plasma nicotine will be crucial to such study.

We thank Jean Crutch and Serena Dalrymple for secretarial help, and the Medical Research Council and the Department of Health and Social Security for financial support, but most of all the volunteers who each submitted to eight venepunctures.

\section{References}

1 Russell, M. A. H., Lancet, 1974, 1, 254. .

3 Tshton, H., and Watson, D. W., British Medical Fournal, 1970, 3, 679.

3 Turner, J. A. M., Sillett, R. W., and Ball, K. P., Lancet, 1974, 2, 737. $1972,48,1765$.

5 Feyerabend, C., Levitt, T., and Russell, M. A. H., fournal of Pharmacy and Pharmacology, in press.

6 Russell, M. A. H., Cole, P. V., and Brown, E., Lancet, 1973, 1, 576.

7 Russell, M. A. H., et al., British Medical fournal, 1973, 4, 512.

8 Isaac, P. F., and Rand, M. J., Nature, 1972, 236, 308

Ashton, H., et al., Electroencephalography and Clinical Neurophysiology, $1974,37,59$.

10 Armitage, A. K., et al., British Fournal of Clinical Pharmacology, 1974, $1,180$. 